\title{
Traumatized Children, Violent Single Mother Headed Family and Legal Aid
}

\author{
Youxin Li1*Samina Nawshin2 \\ 1. Professor: Financial Law, Guanghua Law School, Zhejiang University, Hangzhou,China-310008 \\ 2. Doctoral Candidate, Guanghua Law School, Zhejiang University,Hangzhou,China-310008
}

\begin{abstract}
Instigation of trauma or distress begins from a quantity of grievance which could be physical or psychological. These two are intensely interrelated with each other. Since mental health controls over the body similarly abusing physically may cause cerebral illness today or later. There are many contention in the society which are apparently taken lightly though these weights heavy for the victims or sufferers. Single mothers are dreadfully defiled by the society as a result their children are also suffering tremendously in silent comportment. This paper has been articulated particularly for traumatized children of single mother headed family who are repeatedly being offended due to direct or indirect abuse by their family members or by the society. In addition, since scarcity of single mother is the key reason of abusive structure and environment of the family thus the aim of this paper is to illustrate protection of these peer of the children by ensuring a special law for single mothers in Bangladesh.
\end{abstract}

Keywords: Single mother, trauma, violence, legislation, legal aid.

DOI: $10.7176 / \mathrm{JLPG} / 84-08$

Publication date: April $30^{\text {th }} 2019$

\section{Introduction}

Indisputably children are the backbone of every society however they could act as an asset and leader only if the children are nurtured with proper care and concern. Appropriate care along with concern for the children starts from thinking about their rights and fundamental or basic needs. First of all the adult society has to understand that children around us or in the society are also human being rather than product or material who belong all kinds of human rights as well as legal rights which are established for their well being by the state and by the universe. It is very unfortunate that due to brutality of adults children especially from distressed mothers are being abused continuously in addition it is depressing that such kind of acts starts from the home. Abusing children in several ways is very common as well as old practice in the society however in my study I have found that the children who are orphan, poor, abandoned and the children and from single parent family are immensely abused by the care giver, custodian parents, relatives, teachers, employer or the other members of the society. According to this profound analysis concerning types of abuse or maltreatment can be alienated as two kinds by direct abuse and indirect abuse. According to a research of Family Structure and Children's Health in the United States in 2010,the relative risk that children from a single-parent family would be physically abused or neglected more than doubled than children live with married parents. Direct abuse can be illustrated as attacking physically by direct hitting, hurting, poking, pinching, choking, pushing or directly verbally insulting, scolding or using cane or any stiff objects to hurt. On the other hand, indirect abuse can be characterized by showing fear of harm or punishment. Shelter, pecuniary and other fundamental demands are assured by the male of the family thus the men of the country has started assuming themselves as the supreme power of the association and has made the custom and culture of neglecting the dependant female's and children's essentials, honour as well as emotion and sentiments as well as this picture is severe in case of distressed mothers who are sheltered along with children in any male family member's house. Institution of domestic violence such as threatening, hurting, wounding, insulting bulling and many more take place from this ground. Repeatedly happening of such kinds of offences impact negatively on the children as a result the children depart from the mainstream or go out of the correct track mentally and physically. In my insightful research I have discovered that shocking home environment is responsible for committing suicide, drug addiction, stealing things and some other mental disorder such as schizophrenia, telling lie and many more. Tendency of telling lie is not a mere problem rather it indicates the upbringing system disorder. According to Arnold Goldberg, a renowned professor of psychiatry at Rush Medical College in Chicago "The ability to lie is a human achievement, one of those abilities that tends to set them apart from all other species." Article 19 of United Nations Convention on the Rights of the Child, 1989 has specified that it is obligation for state party to protect the children from all forms of physical or mental violence, injury or abuse, neglect, maltreatment or exploitation, including sexual abuse. It is mandatory to mention that in the article 28(4) of the Constitution of the People's Republic of Bangladesh it is provided that the state can formulate special provisions in support of women or children or for any backward citizen for their advancement. Despite of having influence of international human rights and affirmative declaration from the constitution of Bangladesh to eradicate the uneven sight from the society violation of legal rights are taking place enormously in the society. With the benevolence of legal ground distressing children of single mothers of Bangladesh must get the legal aids and assistance for their well being which can be possible by encompassing a special legislation for single mothers in Bangladesh. It is vastly intended to elaborate the entire crisis and overcome with legal illustrations in the further steps of the work.

\section{Trauma of Children and abusive domestic environment of single mother's family}

Family is the first institution to nurture and build up the nature of the children all over the world. However there are many children around the society who are born to be neglected by the family and society. Children of distressed mothers are the 
dormant victim of shocking domestic environment. Firstly these children lose their identity as human being in the society as soon as they are discarded or neglected by the fathers. They become burden to the society as most of the times the resources for living become extremely limited. In addition, some children may stay with the mother but deficiency of financial resources make the distressed mother violent or abusive. Such type of children never gets recognition as human being thus humiliation, harassment, unnecessary severe punishment, threatening becomes regular instance for them which develops trauma inside them. Despite of positive mental and physiological growth they fall into darkness from the begging of their life. Again there are some children who used to live in better position with both parents but divorce and separation of the parents makes drastic change in their life. Thus most of the times they take shelter with the mother in any relative's house or the mothers migrate in another place keeping the children to other caregivers in search of the job and from the care giver they experience harsh, brutal and offensive behaviour from the domestic atmosphere. Gradually these children go out of the path due to hidden anguish and unhappy life as there is nobody to hear their emotions and problems. Out of trauma children try to find a new world around them apart from the violent family and by this way they enter into a wrong ,unethical and unlawful way of life. The acts or omissions done by traumatic children are illustrated elaborately in the imminent discussion of the thesis.

\subsection{Mythomania syndrome among the children of negligent family atmosphere}

The term 'Mythomania' has derived from the Greek word 'mythos' which means 'lie' and the word 'mania' is 'compulsion'. Mythomania is a kind of anxiety disorder therefore it can be said that it is not a legal issue. Since Bangladesh is a signatory party of Convention on the Rights of the Child and according to article 19(1) the children are entitled to get favorable atmosphere at home for their proper growth of mental and physical health. However the structure of single mother headed family is infringing this rights of the children therefore it must be taken under direct legal concern. According to experts from the Instituto Mexicano Del Seguro Social, 'Mythomania' is a dilemma that also frequently affects people with low selfesteem, they lay to build themselves feel important and since they are not competent to communicate well with other people. They are able to draw attention by overstate or making up legend or anecdotes (Victoria,2017). "It's a psychological condition which leads the person to distort reality, and which, in the majority of cases, is found in people with low selfesteem who seek attention from others" (J.Duque).The children from single mother headed family do not have any importance in the family rather than an extra trouble so they always try to make them important to others. Moreover, habit of telling lie originated from violent family environment of the children as most of the children of broken family stay with other relatives. As a result false allegation by other members for many reasons is very common for them. As children are not eligible to express the facts thus it's easy to point finger on them. Gradually for personal safety or to be exempted for punishment they grasp the habit of telling lie. In a study it has been found that children living with married parents are less likely to be abused or neglected and almost one million children in Sweden demonstrated that children growing up with single parents were more than twice as likely to experience a serious psychiatric disorder (Brown J.).However unfortunately these sensitive issues are completely unseen in Bangladesh.

\subsection{Kleptomania or habit of stealing things by underprivileged children}

'Kleptomania' is a kind of mental disease that means regular malfunction to resist the desire to steal things. Most of the cases of kleptomania, the patient of this disorder steals belongings that they don't need even (Goldman MPJ,2017). Although it is a mental impairment but as it is happening for breach of international conventional rights in which Bangladesh has ratified in 1989. This treaty is known as Convention on Rights of the Child and according to Article 19(1) of it negligent, violence or any form of abuse which distract the mental condition of children will be amount of violation of human right and state party is under obligation for taking necessary measures to prevent this form of violation. It is very unfortunate for the society that due to negligence towards single mothers a large number of children are getting mentally sick silently. Apparently they are blamed with the name of thief or punished as an offender. However in my study I have found that stealing thing is not always about criminal state of mind rather it is a kind mental disorder. To establish this point I have gone through different medical journals and books based on Kleptomania. According to a study by American Academy of Child \& Adolescent Psychiatry 'while stealing in older children is relentless it indicates behavioral or emotional developmental problems and can be caused by an unstable home life.' Unpleasant family environment of single mother headed family is originating this kinds of children in Bangladesh. In 2016 according to a news report, a 13 years old boy was beaten brutally by his maternal uncle for stealing things in regularly from home and school. According to the caregiver uncle the boy is his sister's son and he is living with him after the boy's father divorced her mother before three years, and stealing is common habit of the boy. Every day he is stealing something from home and to make him aware the uncle gave him severe punishment. As the boy was punished brutally and about to die a human right organization took this criminal offence under their supervision and took the victim under their custody. According to the officials of that organization there is a medical ground of stealing things by the boy as our team has admitted the boy to the intensive care unit of the specialized children hospital. Moreover doctor has stated that this kind of activity is called Kleptomania which has grown specially based on the inattentive and vulnerable home environment. According to the specialist of a physiological centre many patients come to take counseling for Kleptomania whose family environment and history is worse. The centre found at least two kleptomania patients yearly out of the three who are minor and they are from single parent family. Therefore it can be said that unknowingly by negligent behaviour the state is producing mentally ill nation for the future which must be stopped as immediate as possible. Mentally distressed children make them habitual with different wrong habits. As per American Academy of child and Adolescent Psychiatry the children may be expressing their anger or trying to "get even" with his or her parents or the stolen object may become a substitute for love or affection to them. These children think that all the people around them belongs all kinds of necessary substances and they are taking advantages of all resources. Gradually and unknowingly they become furious inside and start stealing things from others. 


\subsection{Drug Exploitations by single mother's children}

Assessment by International Labour Organization (ILO) found that the children from the poorest families and worse family environment, who are in practice of low educational accomplishment, and found in drug trade due to economic inevitability, wrong friendships along with police extortion. Apparently these problems might be seen as social problems however these kinds of crisis directly originates legal issues. Since drug abuse or trade or dealing of drugs is prohibited by law. Abusive structure of single mother headed family is enlarging the pasture of such crime. Research on Family and Social Factor (USA, 2017) suggests that children raised in supportive, affectionate and accepting home environment are less likely to become socially deviant. Consequently children rejected by parents are most likely to become delinquent. Negative family conditions and delinquent peers are seen as significant contributors in the expansion of drug misuse behaviour. A study has been conducted by Multivariate Analysis of Variance (MANOVA) based on the family structure such as dual-parent, mother-only, father-only) focusing respondent's gender and grade in school (8th, 10th, 12th). The study observed 37,507 children with complete data in the research where it has been found approximately $78 \%$ reported living in a both parent household, 8,334 children living with only one parent, $82.5 \%$ resided in mother only households. This study has found that the use of marijuana, inhalants, and amphetamines among single mother's household is more than dual parents. In my view, this group of juveniles become very confused about their identity and social recognition as a result they start live in the world of frustration. They desire a radical relief from the life of humiliation and violence on them along with their mothers. Deviant group in the society is very clever to seize the attention of this group. Unknowingly they enter in to the world of drugs. Juveniles from broken family structure are found highly correlated with misuse of drugs where juveniles of both parents are less related with misuse of drugs (Amato PR). This peer is not only the consumer of the drugs rather they are also used as drug dealer in exchange of money. From the research of the Ministry of Home Affairs for Bangladesh observes National Child Rights Week 2016 from September 29 to October 5 has found that around $44 \%$ of the street children in the country are involved in drug peddling. It is important to mention here that most of the street children are from either single parent family or has no identity. According to the report seasoned criminals recruit street children because they are difficult to trace because these children do not have specific recognition. Bangladesh Narcotic Control Act has been formed in 1990 to control dealings or trade of various kinds of drugs. This act has been amended in 2018 after ratifying United Nations Convention of Drug Trafficking and Narcotic Control. According to this law for dealing drugs imprisonment may extent up to 15 years and in some cases it may extend up to life imprisonment. Only because of family structure a large number of children are becoming drug abuser in the society. Nevertheless a complete legislation for single mother's is mandatory to provide a sound family environment for upbringing healthy children.

\subsection{Tendency of committing suicide by disgraced children}

Social Isolation is a big issue to commit suicide. According to French philosopher Emily Durkheim 'When a man becomes socially isolated or feels that he has no place in the society he destroys himself. It is called Egoistic suicide' these group of children feels that they are alone in the world while other children have everything and enjoying all of their rights but they are just a matter of negligent. They become isolated by the family and society and commit suicide. In a profound article name 'The Burden of Suicide in Rural Bangladesh: Magnitude and Risk Factors' it is found that "Psychological, familial, social, and cultural factors risk factors that have been identified to influence adolescents to commit suicide include low socio-economic and educational status, family history of suicide, parental separation, divorce, or death, poor relationship with family and peers, social contagion, prevalence of psychiatric disorder, psychological stressors, sexual abuse, substance abuse, social deprivation are also responsible." Violent family structure is abetting the children to commit suicide however these offences are not taking in the concern in this way rather these are comprehending as mere social problems. According to section 306 of Penal Code of Bangladesh, 1860 whoever abet or instigate any person to for committing suicide is shall be punished under this law. Apparently these can be seen as social problem however these are the violation of human rights as well since the abusive members of the broken family directly or indirectly instigating the minors toward committing suicide. Such as these children are not allowed to participate in social activities moreover most of the time they are being emotionally abused by mockery or harassment by others. Sometimes they are tortured physically too in the name of punishment out of rage of the adult member as these minors are taken as unwanted lumber in the family. As soon as the single mothers issue will become a concern of special law instigation for committing suicide will be lesser and tendency of it among children can be minimized.

\subsection{Other criminal activities by the dishonored children}

According to Dhaka Chief Metropolitan Police (DCMP) it is found that juvenile of Dhaka city are becoming more aggressive than the wanted criminal. According to a report of Bangladesh Bureau of Statistics, around 40 million children of Bangladesh between the age of 5 and 17 year and around them 1.3 million children are engaged in hazardous jobs, 70\% of them are also involved in criminal activities due to poverty. A large amount them are from broken family and they are used by the godfathers to commit different types of criminal activities. For instance hijacking, drug dealings, eve teasing, demanding money, participating in abduction are the basic job of the broken family boys. They are earning money from these sources. The broken family children face financial crisis thus they set up in their mind to do something and to earn money. They do not consider the consequences of doing criminal activity rather they just take it as their job and involve them in the crime. When a child of violent family sees to cry his mother all the time he determines himself to do something for mother. When a child does not find to do anything to support his mother he starts crime (James Borat,1996). According to social studies scholar Matsueda and Heimer (1987), single parent's supervision on their 
children is less effective, merely because there is only one parent rather than two consequently that makes their children are more likely to enter into contact with delinquent manipulation. Since single mother's of Bangladesh are living immensely vulnerable life due to poverty and social stigma therefore delinquent children are increasing regularly and unfortunately this issue is absolutely out of concern.

\section{Recommendation of the research}

Whenever a civilization becomes uncontrolled, law is the only effective instrument to bring a positive change in the society. Broken family is not a normal matter for the children as they realize the shortage of emotional and financial elements. Moreover when they can realize that they do not have any recognition in the society and they have become a burden for the family as well as mother is suffering to preserve his rights and demands then the innocent mind has nothing except involve in such kind of criminal activity. Mental disorder is a big syndrome among single mothers children. Therefore taking necessary steps to control these things mandatory otherwise the society is going to get a group of violent, criminal and mentally disorder children who will be the burden and barriers for the development of the country. China is becoming a supreme power around the world. Development is impossible without comprising and implementing proper law. In this regards Bangladesh should follow Chinese Marriage and Family law. In the Chinese marriage and family law it is particularly written that both parents have to perform equal duties and responsibilities to up bring the children. In my point of view to overcome from the present situation a particular provision in the proposed legislation for single mothers should be created on the basis of the best interest of the children. More elaborately no matter fathers are getting the custody of children or not nevertheless the children must get full maintenance until they attain their majority regardless the gender of the children. Moreover rehabitation system should be taken by the government for such peer as they have to survive as lumber in other's family. As soon as the financial shortage of single mothers can be removed the vulnerability of children will not appear like the current situation. Therefore, government should financially aid the single mother for the wellbeing of the children. Government should subsidies the mothers at least for a particular term. Such as after coming into knowledge a single mother is suffering for lack of resources the government should step forward to subsidies her a fixed period of time until or unless she can manage a good earning source to maintain herself and this provision must be mentioned in the proposed law. Quota system must be an essential provision in the law for ensuring employment of single mothers. With the quota system by law they will get a source of employment as social rejection is very high for such kinds of victim mothers. Thus a balanced life for the children can be introduced in Bangladesh. It is extremely remarkable in China that there is a particular law known as Mental Health Law which has been amended in 2018. According to Article 21 of this law family members are responsible to create and maintain a standard atmosphere for the children to emphasis positive impact on their mental condition. Therefore it can be observed that positive home environment is indispensable for sound development of mental health of the children thus China has ensured this by making legislation in accordance with social demand. Emphasis on comparative study of law is must for reformation and creation of contemporary and appropriate law for best interest of the children of single mothers.

\section{Concluding remarks}

World Health Organization (WHO) has revealed that however mental illness or stress related emotional disorders starts from depression and family structure but most cases remain unnoticed, concealed and untreated. A research said that about 16 to 18 per cent of children and adolescents are suffering from mental disorders in Bangladesh (Dr. S M Yasir Arafat). In a study by World Health Organization it has been found that in Bangladesh among students aged 13-17, 4\% of boys and $6 \%$ of girls consider attempting suicide due to stress disorder. The limitation of my study was less reported cases and a very small number of research regarding this issue in Bangladesh however I have managed some scholarly research by Department of Psychiatry in which has it was found that in general $15.2 \%$ and $18.4 \%$ children are suffering from psychiatric disorder due to family structure. The same study has been found that frequency of behavioral and emotional disorders was $40.35 \%$ among the children. This result indicates that higher prevalence of psychiatric morbidity among orphan children than general children and adolescents who are living with their both parents(Wasima Rahman). From the aforementioned information it can be said that condition of the children of single mother's house hold is severe in Bangladesh. Development of nation is impossible without sound children and wellbeing of children is not viable without secured life of mother as mother is the first and most trusted shelter for the children. To maintain the stability in the society survival of single mothers should be secured by the proposed legislation. As soon as the mothers can enjoy the human rights the scarcity of life will be decrease. If the mother's right can be secured by the law then related problems like traumatic children will appear less in the society. One of the key reasons to create shocking children is defenselessness of single mothers. Single mother headed family has to suffer not only in financial basis rather in emotional issues also. Impact of such situations highly affects to the children. As a result the insufficiency in the society is moving in cyclic order such as mothers are being deprived from their human rights as a result they cannot support to preserve their children's right and again involvement in crime, deviant activity and mental problem among the children are raising immensely. Therefore the root cause is the disregard and undefended single mothers by the law in the society. Their off spring are becoming crooked from the mainstream however they are the essential part and member of the society. If the single mothers can be placed firmly in the society by law then children do not have to go through a hectic life. Thus to provide them right track to come forward making a law regarding single mother is undoubtedly important. Since the proposed law is in regard to support the single mothers thus the law should have to provide legal provisions for mothers keeping the best interest of the children in the mind. Contemporary formation of law can transform the present condition of the violent single mother headed family environment which is immensely significant for the country. 


\section{References}

Brown J., Cohen P., Johnson J.G., and Salzinger S. 1998. A longitudinal analysis of risk factors for child maltreatment: Findings of a 17 year prospective study of officially recorded and self-reported child abuse and neglect. Child Abuse Negl 22: $1065-78$

Constitution of People's Republic of Bangladesh

Convention on the Rights of the Child, 1989

D. Souza' The impact of drug dealings ' (2003)ILO<https://www.ohchr.org/documents.ilo>accessed23May2017 Drug Investigation Authority, Drug and Society ( Social Welfare Com No245,2016) para34

Department of Health and Mental Disorder, 'Reforming Children Thoughts'(Health Com No124,2015)para 56 Elezabith Honer'Kleptomania and Abusive family Survey and Medical

Treatment'(2016)14(2)AHR<http://health.review/ahr.journal/article.org>accessed 20November 2018

Hemovich, Vanessa, and William D Crano. "Family structure and adolescent drug use: an exploration of single-parent families.” Substance use \& misuse vol. 44,14 (2009): 2099-113. doi:10.3109/10826080902858375

Goldman MPJ, 'Kleptomania: making awareness of sense of the

nonsensical'(2011)8(10)<.https://www.ncbi.nlm.nih.gov/pmc/articles/PMC3225132/>accessed 13June 2017 James Borat, Cry of Single Mother and crime of Her Child(First published 1985,Oxford 1996)

Lies Can Point to Mental Disorders or Signal Normal Growth, Daniel Goleman (May 17, 1988)

Penal Code, 1860

Preventing mental health problems in adolescents, Dr.S M Yasir Arafat

Prevalence of Behavioral and Emotional Disorders among the Orphans and Factors

Associated with this Disease,Wasima Rahman

CR. Dent, 'Human Physiology and Impact of Family Environment'(2011)6(3)JCP

Victoria Nicholls, ' Mythomania: When lying is more than just a habit' The Prisma (Spain,31January2012)7 Milon,

'Human Rights Watch has Revealed the Truth' The Observer(Dhaka 25 December 2016)13

Robert. E, 'Habit and Thought of Children'(2012)16(3)ABS<https://journals.sagepub.com >accessed 10 July2017

Shridhar Sharma, 'Family and social factors as predictors of drug misuse and delinquent behaviour in juveniles'(2015)22(4)<https://www.researchgate.net/publication/287878652_Family_and_social

_factors_as_predictors_of_drug_misuse_and_delinquent_behavior_in_juveniles>accessed 22 May 2017

Family Structure and Children's Health in the United States 2010 